\title{
Molecular characterization of three novel perforins in common carp (Cyprinus carpio L.) and their expression patterns during larvae ontogeny and in response to immune challenges
}

Ting $\mathrm{Li}^{1 \dagger}$, Lei Wang ${ }^{2,3+}$, Yonghuan Zhang ${ }^{1}$, Xinyi Guo ${ }^{1}$, Xinze Chen ${ }^{4}$, Fumiao Zhang ${ }^{1}$, Guiwen Yang ${ }^{1}$, Wujun Wen ${ }^{*^{*}}$ and Hua Li $i^{*}$ (D)

\begin{abstract}
Background: In the host immune system, perforin is a cytotoxic effector molecule that eliminate virus-infected and malignant cells. Moreover, some recent studies also imply the involvement of perforin in antibacterial immunity. Common carp (Cyprinus carpio L.), one of the most economically important fish species in China, has a high susceptibility to viruses and bacteria. Thus far, in common carp, no data are available regarding the identification and immunologic function of the perforin.

Results: In the present study, the cDNA and genomic DNA sequences of three perforin isoform genes were cloned and characterized in common carp, named CCPRF1, CCPRF2 and CCPRF3. Amino acid sequences of the three CCPRFs were quite different, with identities ranged from 37.3 to $39.5 \%$. Phylogenetic analysis showed that three CCPRFs, each in a separate sub-branch, possessed closer evolutionary relationship with other teleost perforins, especially with cyprinid fishes, than higher vertebrates. Expression analysis revealed that each CCPRF gene was differentially expressed in all of the nine tested tissues. During larvae ontogeny, each CCPRF displayed a distinct expression pattern, while with a common expression peak at 22 days post hatching (dph). Moreover, in vivo or in vitro, after stimulation with polyl:C, LPS and Aeromonas hydrophila, each CCPRF was induced significantly, with differential expression dynamics.

Conclusions: Our findings suggest that perforin might play significant roles in larval immune system and in the immune defense of common carp against viral and bacterial pathogens. Meantime, the differential expression dynamics seem to imply possible different cellular locations or functional differences across various CCPRF isoforms.
\end{abstract}

Keywords: Common carp (Cyprinus carpio L.), Perforin, Evolutionary relationship, Expression pattern

\section{Background}

In mammals, natural killer (NK) cells and $\mathrm{CD}^{+}$cytotoxic $\mathrm{T}$ lymphocytes (CD8 $\left.{ }^{+} \mathrm{CTLs}\right)$ play important roles in the immune-cytotoxic system against virus-infected and tumor cells. In this process, it has been confirmed that perforin plays a crucial role [1]. Moreover, some

\footnotetext{
* Correspondence: wenwj@sdnu.edu.cn; lihua@sdnu.edu.cn

${ }^{\dagger}$ Ting Li and Lei Wang contributed equally to this work.

${ }^{1}$ Shandong Provincial Key Laboratory of Animal Resistance Biology, College

of Life Sciences, Shandong Normal University, Jinan 250014, China

Full list of author information is available at the end of the article
}

recent studies pointed also to the role of perforin in resisting bacterial pathogens [2, 3]. Until now, in addition to these two cytotoxic cells, some studies reported the expression of perforin in other types of cell, including NKT cells [4], effector-like $\gamma \delta$ T cells [5] and some $\mathrm{CD}^{+} \mathrm{T}$ lymphocytes [6].

Perforin is a $60-70 \mathrm{kDa}$ pore-forming glycoprotein, which belongs to the membrane-attack-complex/perforin (MACPF) family $[7,8]$. Mature perforin molecule has three domains: an N-terminal MACPF domain, an intermediate epidermal growth factor (EGF)-like domain

(c) The Author(s). 2018 Open Access This article is distributed under the terms of the Creative Commons Attribution 4.0 International License (http://creativecommons.org/licenses/by/4.0/), which permits unrestricted use, distribution, and reproduction in any medium, provided you give appropriate credit to the original author(s) and the source, provide a link to the Creative Commons license, and indicate if changes were made. The Creative Commons Public Domain Dedication waiver (http://creativecommons.org/publicdomain/zero/1.0/) applies to the data made available in this article, unless otherwise stated. 
and a C-terminal calcium-binding (CalB) domain. Pore formation of perforin depends on these two characteristic domains, in which MACPF is related to pore-forming [9, $10]$ and the CalB motif is related to calcium-dependent membrane binding to target cells [11]. Under normal circumstances, perforin is stored in cytoplasmic secretory granules of NK cells and CTLs. After these cytotoxic cells are activated, monomer perforin polymerizes to form a channel of 5-20 nm in diameter in target cell membranes, leading to the disruption of cell membrane and subsequently the death of target cells [12]. Additionally, the pores formed by perforin allow granzymes (Gzms), serine proteases stored in cytoplasmic granules of NK/CTL cells with perforin, into the cytosol of target cells [13], which will induce the activation of proapoptotic pathways and DNA degradation.

Perforin was first characterized as a lytic pore-forming protein isolated from CTLs in 1985 [14]. In humans and mice, perforin is a single-copy gene, and presently its immunological function has been well studied. In teleosts, until now, the perforin genes have been characterized in 6 species, including Japanese flounder (Paralichtys olivaceus) [15, 16], channel catfish (Ictalurus punctatus) [17], rainbow trout (Oncorhynchus mykiss) [18], ginbuna crucian carp (Carassius auratus langsdorfii) [19], rock bream (Oplegnathus fasciatus) [20, 21] and zebrafish (Danio rerio) [22]. Moreover, different with humans and mice, there are more than one perforin genes in fish genomes $[19,22]$, although only one isoform was reported in some teleosts to date $[16-18,20]$.

Common carp (Cyprinus carpio L.) is one of the most important aquaculture fish species in China and has a high susceptibility to viruses and bacteria. In common carp, although there were data suggesting the existence of a perforin/Gzm pathway like mammals [23], no data are currently available regarding the identification and immune function of the perforin. In the present study, three perforin isoform genes were cloned and characterized from common carp, named $C c$ PRF1, CcPRF2 and CcPRF3 according to their amino acid identities with crucian carp perforins. We studied their evolution and analysed their constitutive expression patterns in healthy carps and during larvae ontogeny. Moreover, gene expression patterns of the three CcPRFs upon polyinosinic-polycytidylic acid (polyI:C) and Aeromonas hydrophila (A. hydrophila) stimulation were determined in vivo. Meanwhile, we isolated leukocytes from the head kidney and peripheral blood of common carp, and analysed polyI:C and lipopolysaccharides (LPS)-induced expression of $C c$ PRFs and $C D 8 \alpha$ gene in vitro.

\section{Methods}

Fish rearing and sample collection

Healthy common carps, with a body weight of $80 \pm 5 \mathrm{~g}$, were obtained from the Fresh Water Fishery Research
Institute of Shandong Province, China. Before the start of experiments, fish were acclimated to the laboratory environment in a recirculating freshwater system at $20^{\circ} \mathrm{C}$ for 2 weeks and fed once daily with commercial carp pellets. Four healthy fish were euthanatized by anesthesia in $100 \mathrm{mg} / \mathrm{L}$ MS222 (Sigma, USA), and the tissue samples, including those of the liver, spleen, head kidney, foregut, hindgut, gill, skin, brain and muscle, were isolated for RNA extraction.

To investigate gene expression patterns of three $C c$ PRFs during embryonic and early larval stages, four pairs of parent fish were selected for artificial propagation, which was performed based on a previous study [24]. Fertilized eggs were incubated in a water tank at $28-30{ }^{\circ} \mathrm{C}$ with enough oxygen. At 2 days post hatching (dph), the larvae started to be fed with aseptic soymilk. During $9 \mathrm{dph}-22 \mathrm{dph}$, the juvenile fish were fed with fine-grained fish meal. At various developmental stages with blastula stage ( 1 days post fertilization, $1 \mathrm{dpf}$ ), optic primordium appearance ( $2 \mathrm{dpf}), 1 \mathrm{dph}, 2 \mathrm{dph}, 4 \mathrm{dph}, 8$ $\mathrm{dph}, 14 \mathrm{dph}$ and $22 \mathrm{dph}$, five embryos or larvae were sampled randomly for RNA extraction.

\section{RNA extraction and CDNA preparation}

Total RNA was extracted from the tissue, embryo and larva samples using the RNAsimple Total RNA Kit (Tiangen, China). The concentration and quality of total RNA was measured using a spectrophotometer. The RNA template was subjected to reverse transcription into first-strand cDNA using the FastQuent RT Kit (with gDNase) (Tiangen, China).

\section{CDNA and genomic DNA cloning of CCPRF1, CCPRF2 and CCPRF3 genes}

To clone the cDNA sequences of perforin from common carp, three pairs of primers, PRF1-F/PRF1-R, PRF2-F/ PRF2-R and PRF3-F/PRF3-R, were designed based on the conserved regions of published perforin cDNA sequences from other fish species. The first-strand cDNA synthesized by spleen-derived RNA served as a template to amplify the corresponding cDNA sequences of CcPRF1, CcPRF2 and CcPRF3, and a 405-bp cDNA fragment of CcPRF1, a 611-bp of CcPRF2 and a 1367-bp of CcPRF3 were obtained. PCR was performed using the following steps: denaturation at $95^{\circ} \mathrm{C}$ for $5 \mathrm{~min}$, followed by $35 \mathrm{cy}-$ cles of $95^{\circ} \mathrm{C}$ for $30 \mathrm{~s}, 60^{\circ} \mathrm{C}$ for $30 \mathrm{~s}$, and $72{ }^{\circ} \mathrm{C}$ for $2 \mathrm{~min}$, with a final extension step of $72{ }^{\circ} \mathrm{C}$ for $10 \mathrm{~min}$. Next, the full-length cDNA sequences of $C c$ PRF1, $C c P R F 2$ and CcPRF3 were obtained by the rapid amplification of the cDNA ends (RACE) method with a 5'-Full RACE and 3'-Full RACE Core Set Kit (TaKaRa, Japan). The procedure was carried out as described in the user manual, and two rounds of PCR were performed to amplify the $5^{\prime}$ and 
3' flanking regions. The primers used for cDNA cloning are shown in Additional file 1: Table S1.

To obtain the DNA sequences of three CcPRF genes, genomic DNA was purified from the spleen of common carp with the Genomic DNA Kit (Tiangen, China). Based on CcPRF1, CcPRF2 and CcPRF3 cDNA sequences, three, four and three primer pairs were designed respectively, and then their PCR products were analysed and sequenced. The primers used for DNA cloning are shown in Additional file 2: Table S2.

All PCR products were analysed by $1 \%$ agarose electrophoresis, and the anticipated fragments were purified using the PCR purification kit (Tiangen, China). These fragments were then ligated into the pMD18-T vector (TaKaRa, Japan), transformed into competent Escherichia coli cells DH-5 $\alpha$ and sequenced by BGI China.

\section{Polyl:C and A. hydrophila stimulation in vivo}

The protocols for the immune challenges were carried out as described in previous studies. PolyI:C (Sigma, USA) was suspended in sterile phosphate-buffered saline (PBS) at a final density of $1.6 \mathrm{mg} / \mathrm{ml}$, and twenty-one fish (body mass $80 \pm 5 \mathrm{~g}$ ) were injected intraperitoneally with polyI:C at $500 \mu \mathrm{l}$ per fish [25-27]. A. hydrophila was incubated in Luria-Bertani medium at $28{ }^{\circ} \mathrm{C}$ overnight under continuous shaking. A. hydrophila was inactivated in $0.5 \%$ formaldehyde at $4{ }^{\circ} \mathrm{C}$ overnight and was subsequently suspended in sterile PBS at a final density of $2.0 \times 108 \mathrm{CFU} / \mathrm{ml}$. Twenty-one carps whose body weight was $80 \pm 5 \mathrm{~g}$ were injected intraperitoneally with $500 \mu \mathrm{l}$ of inactivated $A$. hydrophila [28-30].

For the polyI:C-challenged carps, at $3 \mathrm{~h}, 6 \mathrm{~h}, 12 \mathrm{~h}$, $24 \mathrm{~h}, 48 \mathrm{~h}, 72 \mathrm{~h}$ and $120 \mathrm{~h}$ post injection (hpi), three carp individuals were euthanized, and the liver, spleen, head kidney, foregut, hindgut and skin were sampled and kept in liquid nitrogen for total RNA extraction. For A. hydrophila-challenged carps, at 3, 6, 12, 24, 72 and $168 \mathrm{hpi}$, three fish were dissected, and the same tissues as those of polyI:C-stimulated group were selected for analysis. In addition, three un-stimulated fish served as control group.

\section{Isolation and stimulation of peripheral blood leukocytes (PBLs) and head kidney leukocytes (HKLs)}

The method for isolating common carp PBLs was described in previous reports [31]. Heparinized blood samples were taken from the caudal blood vessel and diluted with an equal volume of complete media (incomplete L-15 medium (Gibco, USA) containing 10\% fetal calf serum (FCS), $100 \mathrm{U} / \mathrm{ml}$ penicillin and $100 \mu \mathrm{g} / \mathrm{ml}$ streptomycin). Then, the resulting diluted blood was placed onto $65 \%$ percoll density cushions (Sigma, USA) and centrifuged at $2500 \mathrm{rpm}$ for $30 \mathrm{~min}$ at normal temperature. The layer of PBLs was collected and washed three times with
PBS. The method for isolating common carp HKLs was performed based on previously described protocols [32]. Healthy common carp, with a body weight of $80 \mathrm{~g}$, was obtained from the Fresh Water Fishery Research Institute of Shandong Province and raised in a recirculating freshwater system. The tissue head kidney was collected from freshly killed carp under sterile conditions, pressed with a plunger through a $100-\mu \mathrm{m}$ sterile nylon mesh and rinsed with incomplete Leibovitz's L-15 medium (Gibco, USA). Cell isolation was performed using a 34/51\% non-continuous Percoll gradient (Sigma, USA). After $30 \mathrm{~min}$ of centrifugation at $1500 \mathrm{rpm}$, the cell layer present in interphase was collected and then washed three times with PBS. Finally, the cells isolated from heparinized blood and head kidney were individually resuspended in the complete media and cultured in 24-well plates at $25^{\circ} \mathrm{C}$.

After incubation overnight, drug treatment of polyI:C and LPS $(10 \mu \mathrm{g} / \mathrm{ml})$ (Sigma, USA) was performed in these two groups. At $3 \mathrm{~h}, 6 \mathrm{~h}, 12 \mathrm{~h}$ and $24 \mathrm{~h}$ post stimulation, the cells were harvested for RNA extraction. Additionally, the un-stimulated cells served as control group.

\section{Real-time PCR}

Gene expression analyses of CcPRF1, CcPRF2, CcPRF3, and CD8 $\alpha$ were performed on a LightCycler $^{\oplus} 96$ Real-time PCR System (Roche, Switzerland) using TransStart ${ }^{\circ}$ Tip Green qPCR SuperMix (Transgen, China). The program was as follows: $94{ }^{\circ} \mathrm{C}$ for $30 \mathrm{~s}$, followed by 40 cycles of $94{ }^{\circ} \mathrm{C}$ for $5 \mathrm{~s}, 58{ }^{\circ} \mathrm{C}$ for $15 \mathrm{~s}$ and $72{ }^{\circ} \mathrm{C}$ for $10 \mathrm{~s}$. Finally, melt curve analysis was carried out to verify the presence of one single PCR product at the end of the assay. Each sample was analysed in triplicate, and the $40 \mathrm{~S}$ ribosomal protein S11 gene served as a housekeeping gene to normalize the mRNA expression. The relative gene expression was determined using the $2^{-\Delta \Delta C T}$ method [33], and the primers used in Real-time PCR are shown in Additional file 3: Table S3.

\section{Bioinformatics and statistical analyses}

The putative open reading frames (ORFs) and protein prediction were analysed with EditSeq within DNASTAR. The protein domains were predicted using the simple modular architecture research tool (SMART) (http://smart.embl-heidelberg.de/). Phylogenetic trees were generated with MEGA 6.0 using the neighbor-joining (NJ) method, in which the Jones-Taylor-Thornton (JTT) model was used as an amino acid substitution model. The protein tertiary structures were predicted by SWISS-MODEL (https:// swissmodel.expasy.org/). GeneBank accession numbers used in phylogenetic and homology analyses are shown in Additional file 4: Table S4 and Additional file 5: Table S5.

The differences in relative gene expression between the stimulated group and control group $(0 \mathrm{~h})$ were conducted using two-way analysis of variance (ANOVA) in 
Graphpad Prism 5.0 and were considered significant when $p<0.05$.

\section{Results}

Characterization of three CCPRF CDNA sequences

The full-length cDNA sequences of $C c$ PRF1, CcPRF2 and CcPRF3 were 1869 bp, 1971 bp and 1966 bp (Fig. 1a, b, c), and their GenBank accession numbers were MH271082, MH271083 and MH271084, respectively. CcPRF1 comprised a 60-bp 5'-untranslated region (UTR), an ORF of 1767 bp encoding 588 amino acids and a 42-bp 3'-UTR. CcPRF2 comprised a 40-bp 5'-UTR, an ORF of 1677 bp encoding 558 amino acids and a 254-bp 3'-UTR. CcPRF3 was composed of a 66-bp 5'-UTR, an ORF of 1728 bp encoding 575 amino acids and a 172-bp 3'-UTR. Protein domain prediction showed that each $C c$ PRF contained a signal peptide domain, a MACPF domain and a CalB domain (Fig. 1d). The locations of the MACPF domain for $C c$ PRF1, CcPRF2 and $C c$ PRF3 were residues $163-365,154-354$ and 160
358 , respectively, and the CalB domains were located at residues 412-511, 398-497 and 405-499, respectively.

\section{Genomic structures of three CcPRFs}

CcPRF1 and CcPRF2 genes contained five exons and four introns, which were $3003 \mathrm{bp}$ and $6046 \mathrm{bp}$, respectively. CcPRF3 DNA was $2761 \mathrm{bp}$, comprising four exons and three introns. The sizes of exons and introns and their position in DNA were indicated in Fig. 2, and the exon-intron splice junctions followed the AG/GT rule (Table 1). In addition, the specific exon and intron sequences of $C c$ PRF1, $C c$ PRF2 and $C c$ PRF3 are listed in Additional file 6; Additional file 7 and Additional file 8, respectively.

\section{Phylogenetic and homology analyses}

Phylogenetic analysis of the MACPF family proteins (perforin, C6, C7, C8, C9) and the MACPF-domain containing protein (macrophage-expressed gene 1, Mpeg-1) showed that the three $\mathrm{CcPRFs}$ and the perforins of other

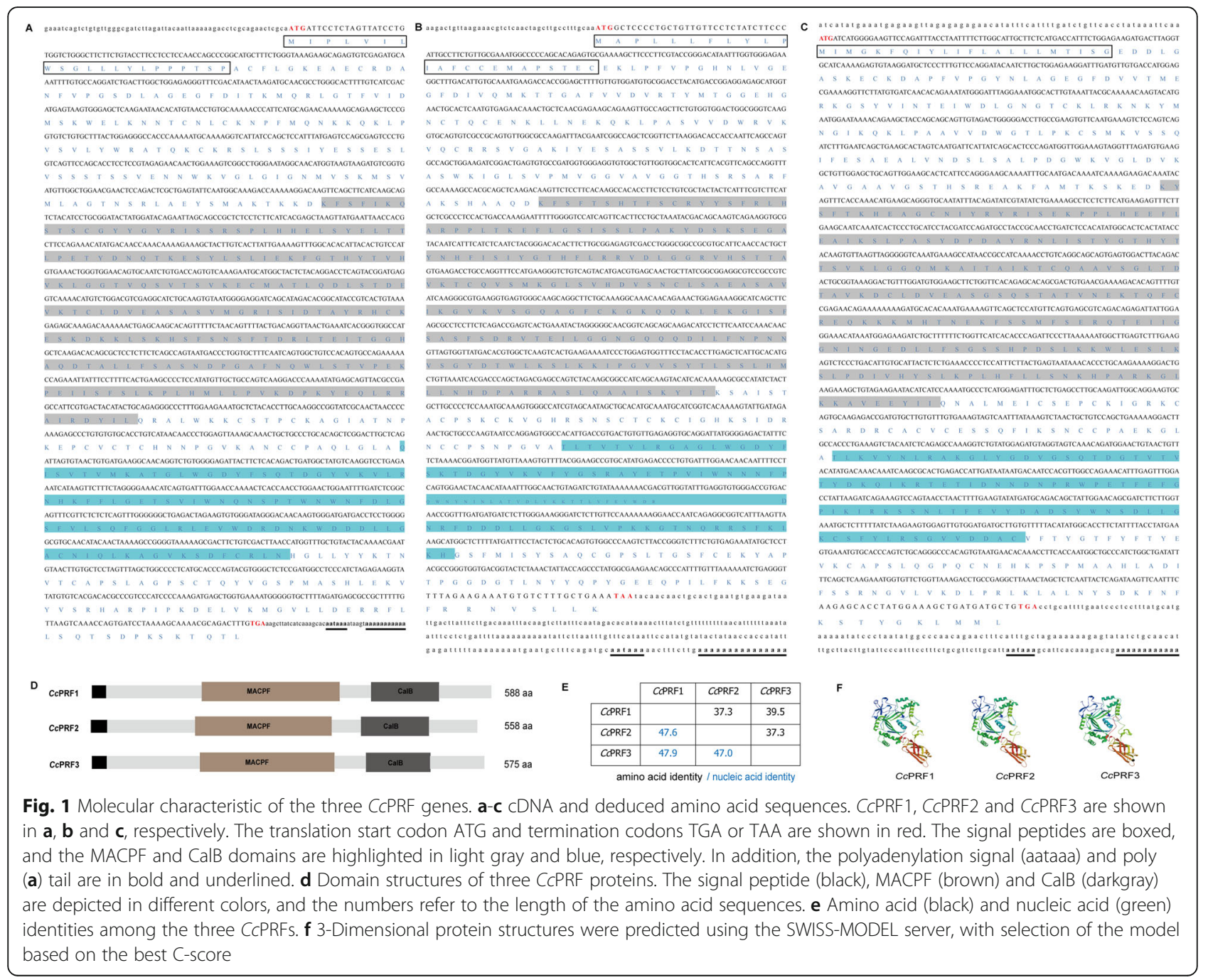




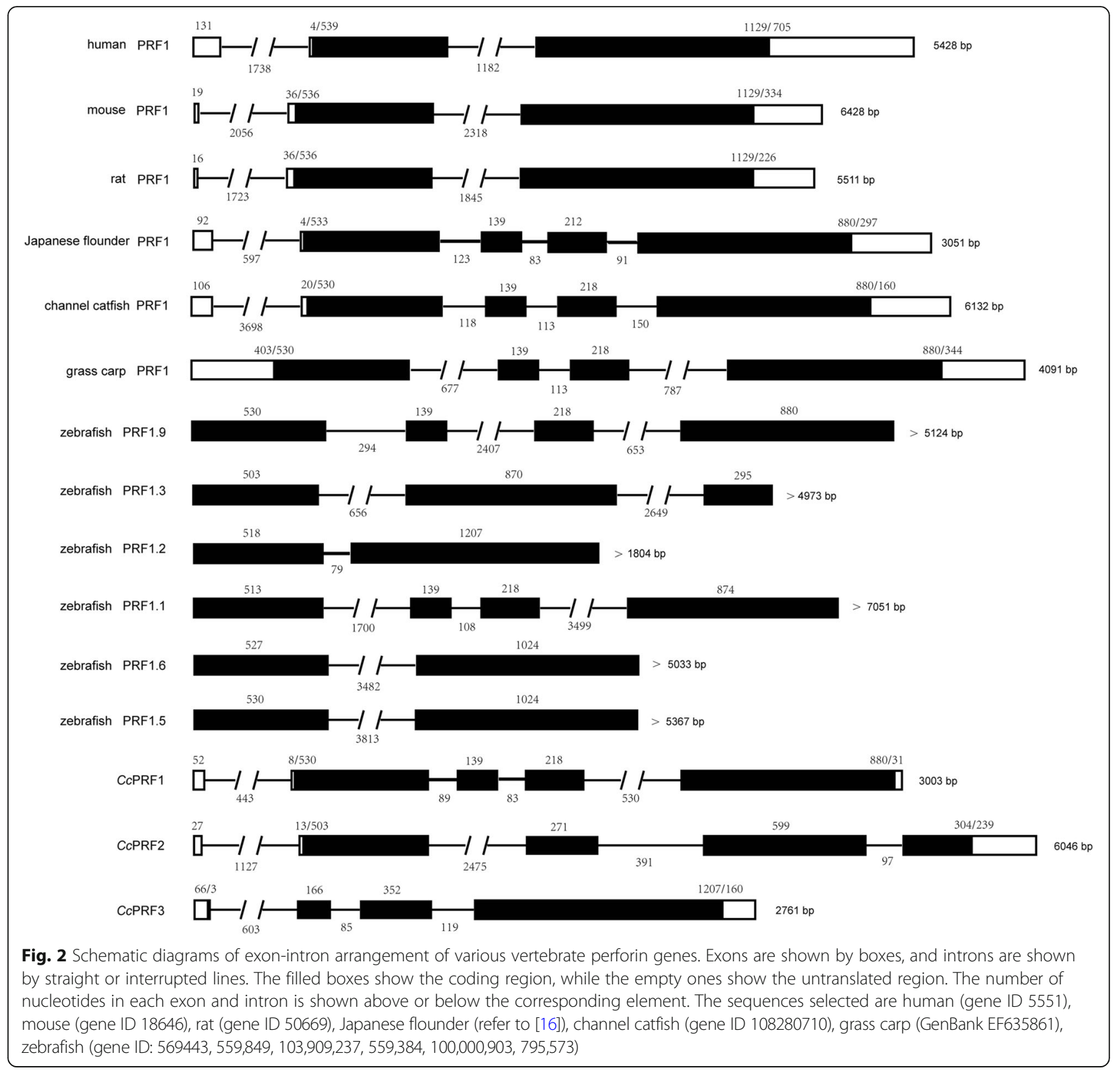

species were clustered in one branch, where fish perforins were separated from the cluster of other species, including the mammals, birds and amphibians (Additional file 9: Figure S1). While for common carp, the three CcPRFs belonged to three different sub-branches, in which each CCPRF was phylogenetically closest to the perforins of other cyprinid fish, such as the ginbuna crucian carp, zebrafish and grass carp (Fig. 3).

Homology analysis showed that CCPRF1 shared the highest amino acid identities with crucian carp PRF1 (86.9\%), grass carp PRF1 (83\%) and zebrafish PRF1.9 (81\%), CcPRF2 with ginbuna crucian carp PRF2 (89.8\%) and zebrafish PRF1.3 (76.6\%), and CcPRF3 with ginbuna crucian carp PRF3 (77.8\%) and zebrafish PRF1.2 (71.0\%).
The amino acid identities of three CcPRFs with the human, mouse, chicken and green anole perforin proteins ranged from 29.2 to $36.8 \%$ (Table 2). Additionally, as shown in Fig. 1e, each $C c$ PRF had less than amino acid $40.0 \%$ identities (37.3-39.5\%) with the other two isoforms.

\section{Tissue distribution of three CCPRFs in healthy common carps}

Each $C c$ PRF was expressed in all the nine tested tissues, including the liver, spleen, head kidney, foregut, hindgut, gill, skin, brain and muscle, with different expression levels in various tissues (Fig. 4a). Moreover, in each tissue, the three CcPRFs also showed differential expression profiles (Fig. 4b). 
Table 1 Intron-exon junctions and flanking sequences of the CCPRF1, CCPRF2 and CCPRF3

\begin{tabular}{|c|c|c|c|c|c|}
\hline Exon no. & Position in DNA & Exon size (bp) & Splice donor & Splice acceptor & Intron size (bp) \\
\hline CCPRF1-1 & $1-52$ & 52 & gtaagtgaaa & atctcagcag & 443 \\
\hline 2 & 496-1033 & 538 & gtaagactta & ctgtcttcag & 89 \\
\hline 3 & $1123-1261$ & 139 & gtaagccaaa & aatctgttag & 83 \\
\hline 4 & 1345-1562 & 218 & $\mathbf{g t t} \operatorname{tgtgctt}$ & tttctacaag & 530 \\
\hline 5 & 2093-3003 & 911 & & & \\
\hline CCPRF2-1 & $1-27$ & 27 & gtaaatatca & tctctttcag & 1127 \\
\hline 2 & $1155-1670$ & 516 & gtaagttctg & ctttcatcag & 2475 \\
\hline 3 & $4146-4416$ & 271 & gtgagtgggc & gggcgtgaag & 391 \\
\hline 4 & $4808-5406$ & 599 & gtaagtggtt & cattttacag & 97 \\
\hline 5 & $5504-6046$ & 543 & & & \\
\hline CCPRF3-1 & $1-69$ & 69 & gtaagaaact & ttcactacag & 603 \\
\hline 2 & $673-838$ & 166 & gttcttatgt & gagcgaaaag & 85 \\
\hline 3 & $924-1275$ & 352 & gttatttttc & ttctttatag & 119 \\
\hline 4 & $1395-2761$ & 1367 & & & \\
\hline
\end{tabular}

Bold text indicates the invariant nucleotides of the exon-intron boundaries

Specifically, the highest expression of CcPRF1 mRNA was detected in the spleen, hindgut, gill, skin and brain, followed by the head kidney and muscle, and very low expression in the foregut and liver. CcPRF2 was mainly distributed in the skin, brain and muscle, with a moderate level of expression observed in the spleen, foregut, hindgut and gill, while low gene expression in the head kidney and liver. For $C c$ PRF3, the mRNA expression was predominantly detected in the hindgut, spleen, head kidney, gill and muscle, followed by the brain and skin, and the lowest level in the foregut and liver.

Overall, in healthy carps, gene expression of CcPRF2 predominated in most of the tested tissues, including the muscle $(94.1 \%)$, skin $(93.1 \%)$, brain (89.6\%), foregut (88.6\%), liver (66.7\%), hindgut (48.3\%) and head kidney (46.9\%). In the spleen and gill, CcPRF1 mRNA levels was the highest. In contrast, $C c$ PRF3 mRNA expression was obviously lower than CcPRF1 and CcPRF2, with the proportion of $23.7 \%, 13.6 \%, 5.4 \%, 4.9 \%, 3.0 \%, 1.8 \%$, $0.5 \%$ and $0.6 \%$ in the head kidney, hindgut, spleen, foregut, gill, muscle, skin and brain, respectively. Moreover, in the nine tested tissues, the brain and skin showed the highest cumulative expression levels of the three $C c$ PRFs.

\section{Ontogeny of three CCPRF genes in common carp larvae} As shown in Fig. 5, we analysed gene expression patterns of the three $C c$ PRFs from blastula stage to $22 \mathrm{dph}$. The results showed that $C$ PRF1 had two expression peaks, with the first at $4 \mathrm{dph}$ and the second at $22 \mathrm{dph}$. As for CcPRF2, after fertilization, its gene expression was up-regulated at embryonic stage and continued to increase up to $22 \mathrm{dph}$. While for CcPRF3, it displayed one expression peak at $22 \mathrm{dph}$. Obviously, the three CcPRFs displayed differential expression patterns in larvae ontogeny, while with a common expression peak at 22 dph.

\section{Expression profiles of three CCPRFs upon polyl:C and $A$. hydrophila in vivo}

After polyI:C stimulation, CcPRF1 gene expression was detected highest at $2 \mathrm{dpi}$ in the liver, spleen, head kidney, foregut and hindgut, with 3.7-fold, 5.4-fold, 1.5-fold, 3.2-fold and 8.3-fold higher expression than the control group, respectively (Fig. 6a, $p<0.05$ or $p<0.01$ ). CcPRF2 mRNA level reached peak values at $2 \mathrm{dpi}$ in the liver, spleen and hindgut, with 2.1-fold, 2.2-fold and 5.8-fold up-regulation, respectively, as compared with the control group (Fig. 6b, $p<0.05$ or $p<0.01$ ). In the head kidney, mRNA expression of $C c$ PRF2 began to increase at $2 \mathrm{dpi}$ and reached a peak at $5 \mathrm{dpi}(2.9$-fold, $p<0.05)$. With regard to $C c$ PRF3, the mRNA expression of CcPRF3 never increased significantly in the analysed tissues, with the exception of the skin (7.5-fold, $p<0.05)$ and head kidney (2.0-fold, $p<0.05$ ) (Fig. 6c). Additionally, in the skin, CcPRF1 and CcPRF2 mRNA levels decreased significantly within $12 \mathrm{hpi}$, and soon afterwards return to the basic expression level (Fig. 6a, b).

After A. hydrophila stimulation, mRNA level of each CCPRF was significantly up-regulated in all the analysed tissues, with large fold-change higher expression than that in the control (Fig. 7a, b, c, $p<0.05, p<0.01$ or $p<0.005$ ). Moreover, similar to polyI:C-stimulated group, the three CcPRFs showed different expression patterns in A. hydrophila-stimulated group. 


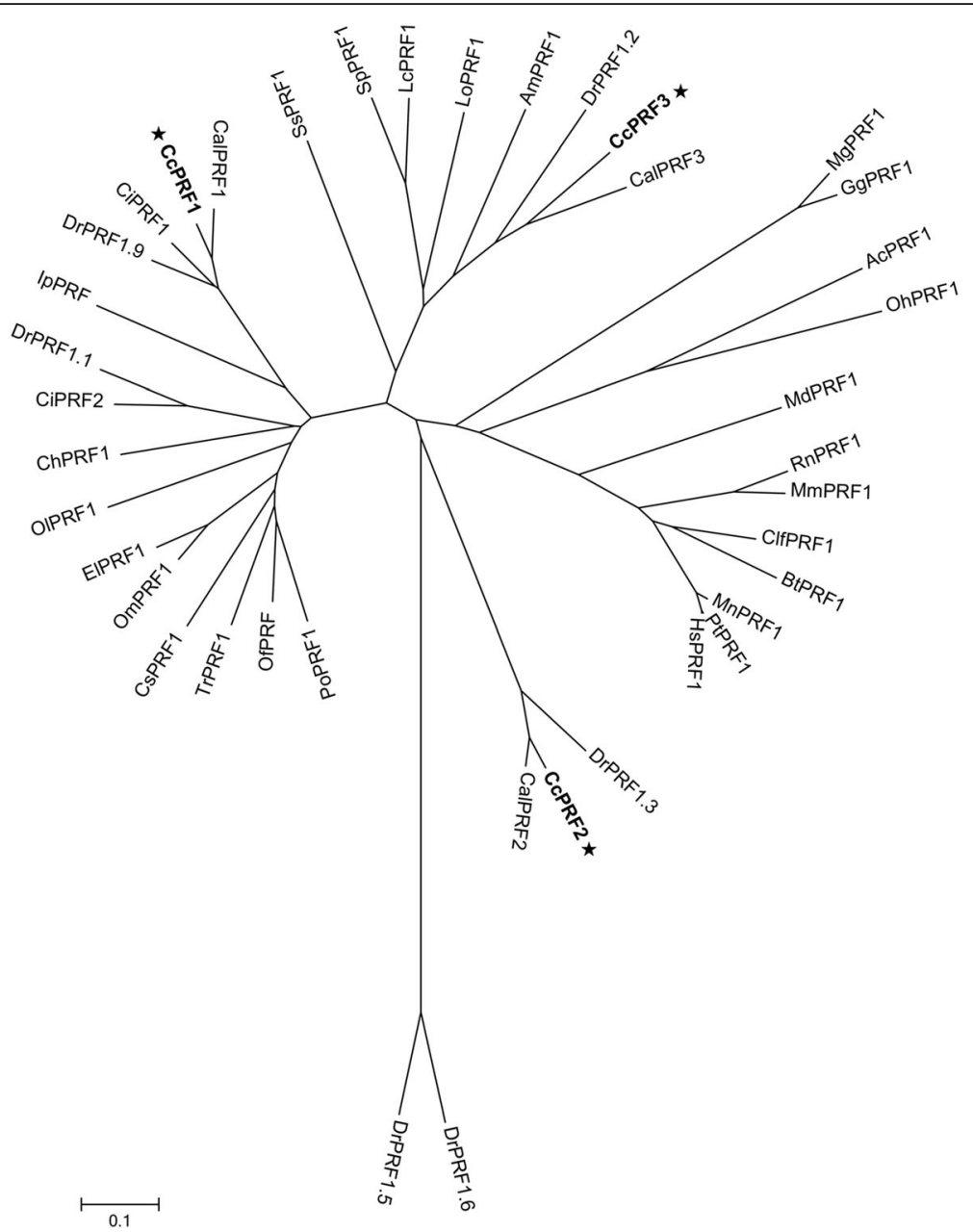

Fig. 3 Phylogenetic analysis of perforin amino acid sequences. Phylogenetic tree is generated using the neighbor-joining (NJ) method in MEGA 6.0, and the GenBank accession numbers used are shown in Additional file 4: Table S4. Hs (Homo sapiens), Pt (Pan troglodytes), Mn (Macaca nemestrina), Rn (Rattus norvegicus), Md (Monodelphis domestica), Mm (Mus musculus), Bt (Bos Taurus), Clf (Canis lupus familiaris), Gg (Gallus gallus), Mg (Meleagris gallopavo), Oh (Ophiophagus hannah), Ac (Anolis carolinensis), El (Esox lucius), Lo (Lepisosteus oculatus), Am (Astyanax mexicanus), Sp(Stegastes partitus), Ol (Oryzias latipes), Tr (Takifugu rubripes), Om (Oncorhynchus mykiss), Lc (Larimichthys crocea), Cs (Cynoglossus semilaevis), Cal (Carassius auratus langsdorfii), Ci (Ctenopharyngodon idella), Po (Paralichthys olivaceus), Of (Oplegnathus fasciatus), Dr. (Danio rerio), Ch (Clupea harengus), Ss (Salmo salar), Ip (Ictalurus punctatus)

\section{Expression profiles of CCPRFs and CD8a in response to polyl:C and LPS in vitro}

To further identify the immunologic function of perforin in common carp, we assayed gene expression of three $\mathrm{CcPRFs}$ and CD $8 \alpha$ upon polyI:C and LPS in PBLs and HKLs.

In PBLs, after polyI:C stimulation, mRNA expression of CcPRF1, CcPRF2 and CcPRF3 reached peak values at 24 hpi, 12 hpi and 6 hpi, respectively, with 2.7-fold, 1.5-fold and 1.4-fold up-regulation, respectively, as compared with the control group (Fig. $8 \mathrm{a}, p<0.05$ or $p<0.01$ ). In response to LPS, CcPRF1 mRNA level reached the highest level at 24 hpi with 1.7-fold higher expression than the control group (Fig. 8c, $p<0.001$ ). Gene expression of CcPRF2 and CcPRF3 was up-regulated to the highest level at $6 \mathrm{hpi}$, with a 3.7-fold and 25.2-fold higher expression than that of the control group, respectively (Fig. 8c, $p<0.01$ or $p<0.005$ ). In HKLs, gene expression of CcPRF1, CcPRF2 and CcPRF3 was up-regulated by polyI:C and increased to peak values at $24 \mathrm{hpi}$, with 3.8-fold, 5.5-fold and 3.0-fold higher expression than the control (Fig. $8 \mathrm{~b}, p<0.01$ or $p<0.005$ ). Upon LPS stimulation, $C c$ PRF1, CcPRF2 and CcPRF3 mRNA expression reached the highest level at $24 \mathrm{hpi}$ as well, with 11.0-fold, 18.4-fold and 5.8-fold higher expression than the control group (Fig. 8d, $p<0.005$ ).

As for CD8 $\alpha$, in PBLs, polyI:C induced the gene expression of CD8 $\alpha$, with 1.5-fold (6 hpi) higher expression than the control group (Fig. 9a, $p<0.05$ ). In response to LPS, CD $8 \alpha$ mRNA expression was increased significantly, with 12.8 -fold (12 hpi) higher expression than the control group (Fig. 9c, $p<0.01$ ). While in HKLs, 
Table 2 Percent identity of perforin proteins between common carp and other species

\begin{tabular}{lllll}
\hline Species & Name & CCPRF1 & CCPRF2 & CCPRF3 \\
\hline Human & PRF1 & 36.1 & 36.7 & 36.2 \\
House mouse & PRF1 & 34.7 & 36.3 & 36.6 \\
Chicken & PRF1 & 28.9 & 31.7 & 30.8 \\
Green anole & PRF1 & 33.5 & 33.2 & 32.1 \\
Fugu rubripes & PRF1 & 49.3 & 36.6 & 38.2 \\
Japanese flounder & PRF1 & 51.0 & 37.8 & 38.0 \\
Atlantic salmon & PRF1 & 41.1 & 36.3 & 43.3 \\
Zebrafish & PRF1.9 & 81.0 & 39.0 & 39.5 \\
& PRF1.2 & 38.0 & 37.1 & 71.0 \\
& PRF1.3 & 36.2 & 76.6 & 36.7 \\
Ginbuna crucian carp & PRF1 & 86.9 & 36.2 & 37.6 \\
& PRF2 & 36.0 & 89.8 & 36.5 \\
& PRF3 & 37.5 & 37.6 & 77.8 \\
Grass carp & PRF1 & 83.0 & 37.9 & 38.4 \\
& PRF2 & 53.7 & 35.6 & 38.9 \\
\hline
\end{tabular}

\section{A}

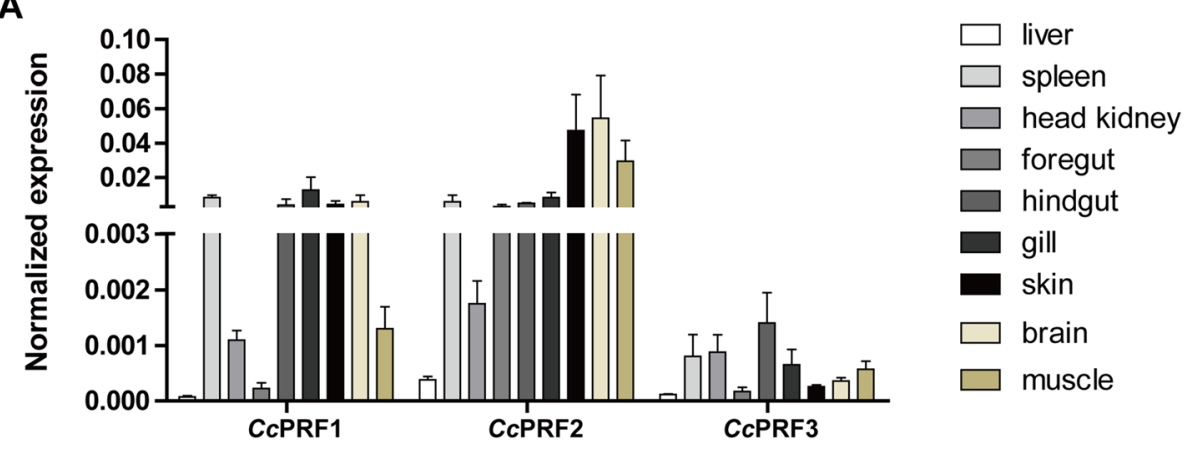

B

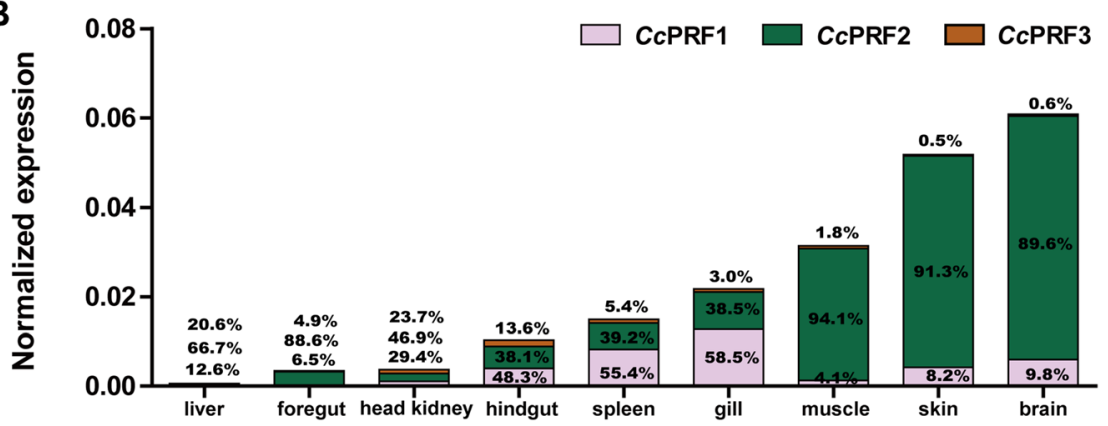

Fig. 4 Constitutive tissue-specific expression of three CCPRF genes in healthy common carps. a Relative expression of three CCPRFs in the nine tissues (the liver, spleen, head kidney, foregut, hindgut, gill, skin, brain and muscle). b Cumulative expression and relative proportion (\%) of three CCPRFs in different tissues. In each tissue, the relative proportion of CCPRF1 (bottom), CCPRF2 (middle) and CCPRF3 (top) were shown with percentage numbers. Relative gene expression level of each CCPRF was detected using real-time PCR. Amplification of S11 in each tissue was performed as an internal control $(n=4)$ upon polyI:C challenge, the gene expression of CD8 $\alpha$ reached the highest level at $24 \mathrm{hpi}$, in which time point the expression level was 28.6-fold higher than the control (Fig. 9b, $p<0.05$ ). In response to LPS, CD8 $\alpha$ mRNA levels reached the highest at $6 \mathrm{hpi}$, with 9.7-fold higher expression than the control (Fig. 9d, $p<0.05$ ).

\section{Discussion}

In the present study, we cloned and confirmed three perforin isoform genes from common carp, named $C c$ PRF1, $C c$ PRF2 and $C c$ PRF3. The three $C c$ PRFs were quite different with each other, with nucleic acid identities of ORF ranged from 47.0 to $47.9 \%$ and amino acid identities from 37.3 to $39.5 \%$ (Fig. 1e). Nevertheless, in the phylogenetic tree of perforin, C6, C7, C8, C9 and Mpeg-1, the same evolutionary branch of CcPRFs with other species' perforins strongly implied that the three $C_{C}$ PRFs all belong to the perforin superfamily (Additional file 9: Figure S1). The three CcPRF proteins were all comprised of a signal peptide, a middle MACPF domain and a C-terminal CalB domain, exhibiting the same domain architecture as mammalian orthologs [34, 35] although the three CcPRFs only shared $34.7-36.7 \%$ amino acid identities with human and mouse perforins 


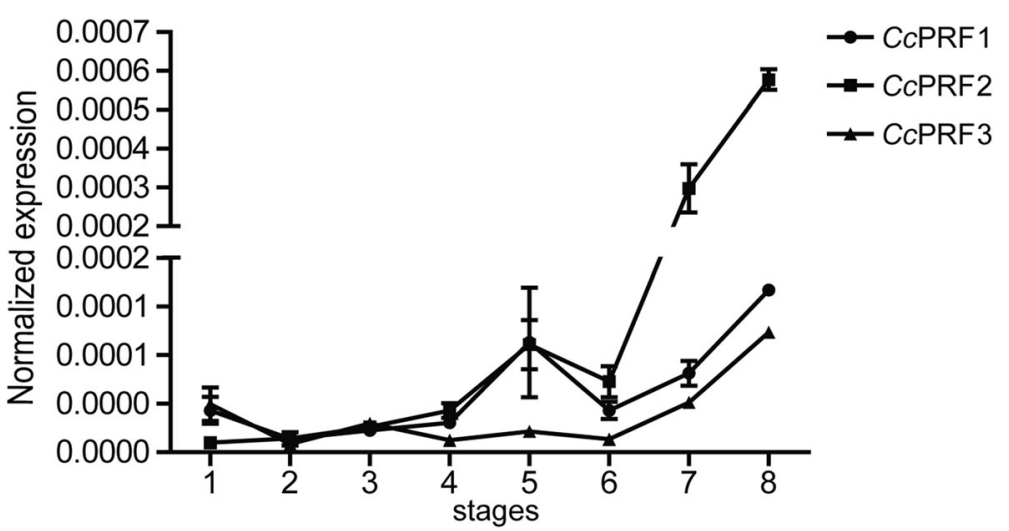

Fig. 5 The mRNA expression patterns of three CCPRF genes during larvae ontogeny. Each CCPRF is shown with a distinct line graph. Abscissa values (1-8) are indicated as 8 developmental stages with (1) blastula stage; (2) optic primordium appearance; (3) 1 dph; (4) 2 dph; (5) 4 dph; (6) $8 \mathrm{dph}$; (7) $14 \mathrm{dph}$; (8) $22 \mathrm{dph}$. The relative expression of each CCPRF is normalized to S11 gene and displayed as the means \pm SD $(n=5)$

(Table 2). Thus, the consistency of CcPRF protein domains with the typical structure of perforin protein implied that $C$ CPRFs might play the similar role as do the other species' perforins [36].

The intron-exon arrangement of perforin gene in humans, mice and rats was conserved, in which they were all comprised of three exons and two introns, and the sizes of the exons located in their ORFs were 536/ 539 and 1129 bp (Fig. 2). However, these characteristics were quite different from that of the three $C c$ PRF genes and other fish perforins, which was in line with the previous suggestion of different genomic structures of the perforin between teleosts and mammals [16]. On the other hand, for CcPRF1, its intron-exon arrangement was similar to that of zebrafish PRF1.9 and grass carp, channel catfish and Japanese flounder PRF1, particularly showing more similarities with grass carp, channel catfish and zebrafish, with the same exon sizes $(530,139$, 218 , 880), than Japanese flounder. CcPRF2 genomic DNA comprised five exons and four introns, and the sizes of the exons located in its ORF were 503, 271, 599 and 304. Similarly, for zebrafish PRF1.3 gene, the size of the first exon located in its ORF was 503 bp as well. And for CcPRF3, the size of the last exon located in
ORF was $1207 \mathrm{bp}$, which was the same as that of zebrafiah PRF1.2 gene. Notably, all these similarities were in line with the phylogenetic relationship of perforin in fish species (Fig. 3). Moreover, although intron/exon arrangement of zebrafish PRF1.5 and PRF1.6 was largely different form that of the three $C c$ PRFs, the exons of these two zebrafish perforins had highly similarities with each other, which was in accordance with their very close evolutionary relationship. Thus, taken together all these results implying that intron-exon organization of perforin gene was in accordance with the evolutionary relationship and species evolution.

Similar to the previous report that under basal conditions 6 zebrafish perforin genes were all expressed in the liver, spleen, kidney, intestine, gill and muscle [22]. Each CcPRF gene was expressed in the nine analysed tissues (the liver, spleen, head kidney, foregut, hindgut, gill, skin, brain and muscle) (Fig. 4). However, it was reported that perforin gene was not able to be detected in the liver, stomach, brain, muscle, fin and eye of Japanese flounder $[15,16]$ and the liver of trout [18]. Although the tissue distribution pattern of perforin was inconsistent in fish species, its gene expression was always detected in the pivotal immune-related tissues (the head kidney, spleen,

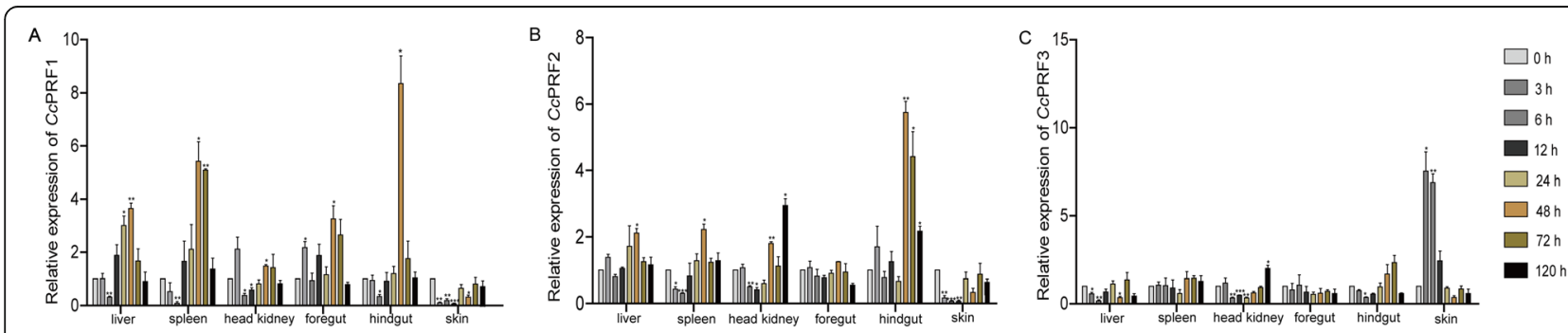

Fig. 6 Gene expression of three CCPRF genes after polyl:C stimulation in vivo. CCPRF1, CCPRF2 and CCPRF3 are shown in a, b and $\mathbf{c}$, respectively. The results are normalized to S11 gene. Data are presented as a fold change of the stimulated group to the un-stimulated group (denoted by $0 \mathrm{~h})$ and displayed as the means \pm SD $(n=3) .{ }^{*} p<0.05,{ }^{* *} p<0.01$ and ${ }^{* * *} p<0.001$ 


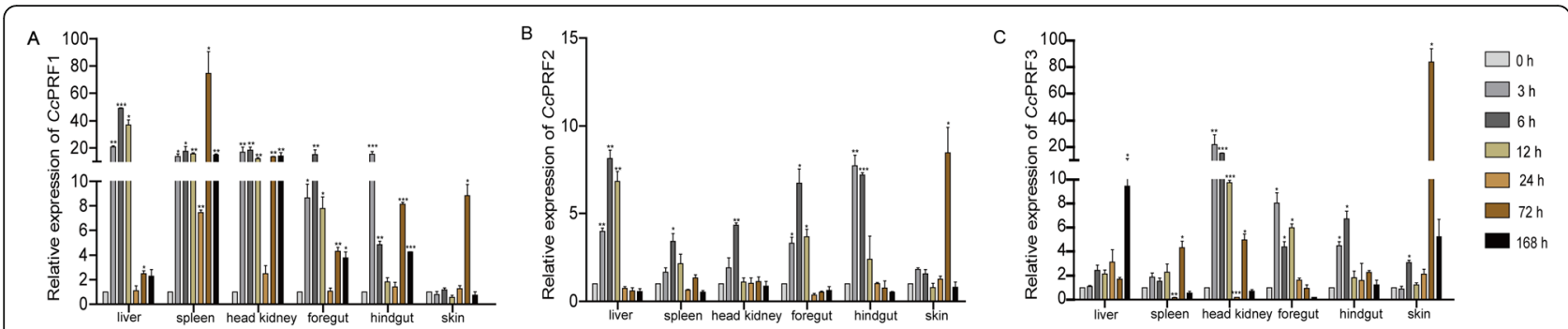

Fig. 7 Gene expression of three CCPRF genes after A. hydrophila stimulation in vivo. CCPRF1, CCPRF2 and CCPRF3 are shown in $\mathbf{a}$, b and $\mathbf{c}$, respectively. The results are normalized to $\mathrm{S11}$ gene. Data are presented as a fold change of the stimulated group to the un-stimulated group (denoted by $0 \mathrm{~h}$ ) and displayed as the means \pm SD $(n=3) .{ }^{*} p<0.05,{ }^{* *} p<0.01$ and ${ }^{* * *} p<0.001$

intestine, gill and skin), at least implying the potential role of fish perforin in the immune system.

Previously, it was shown that the innate immune system is a fundamental defense weapon of fish during early stages of development [37-39]. In the common carp, it was reported that innate immune factors such as C3 and $\alpha 2$-macroglobulin were present before hatching and these factors were involved in the immune defense response during ontogeny of carp [38, 40]. Additionally, in the zebrafish, it was demonstrated that immune system of the larvae was completely mature between 4 and 6 weeks post fertilization [41]. In accordance with this time period, during the larvae ontogeny of zebrafish, expression peaks were observed around the fourth week of development (23 dpf and $29 \mathrm{dpf}$ ) in several perforin genes [22]. Similarly, in the early development stages of

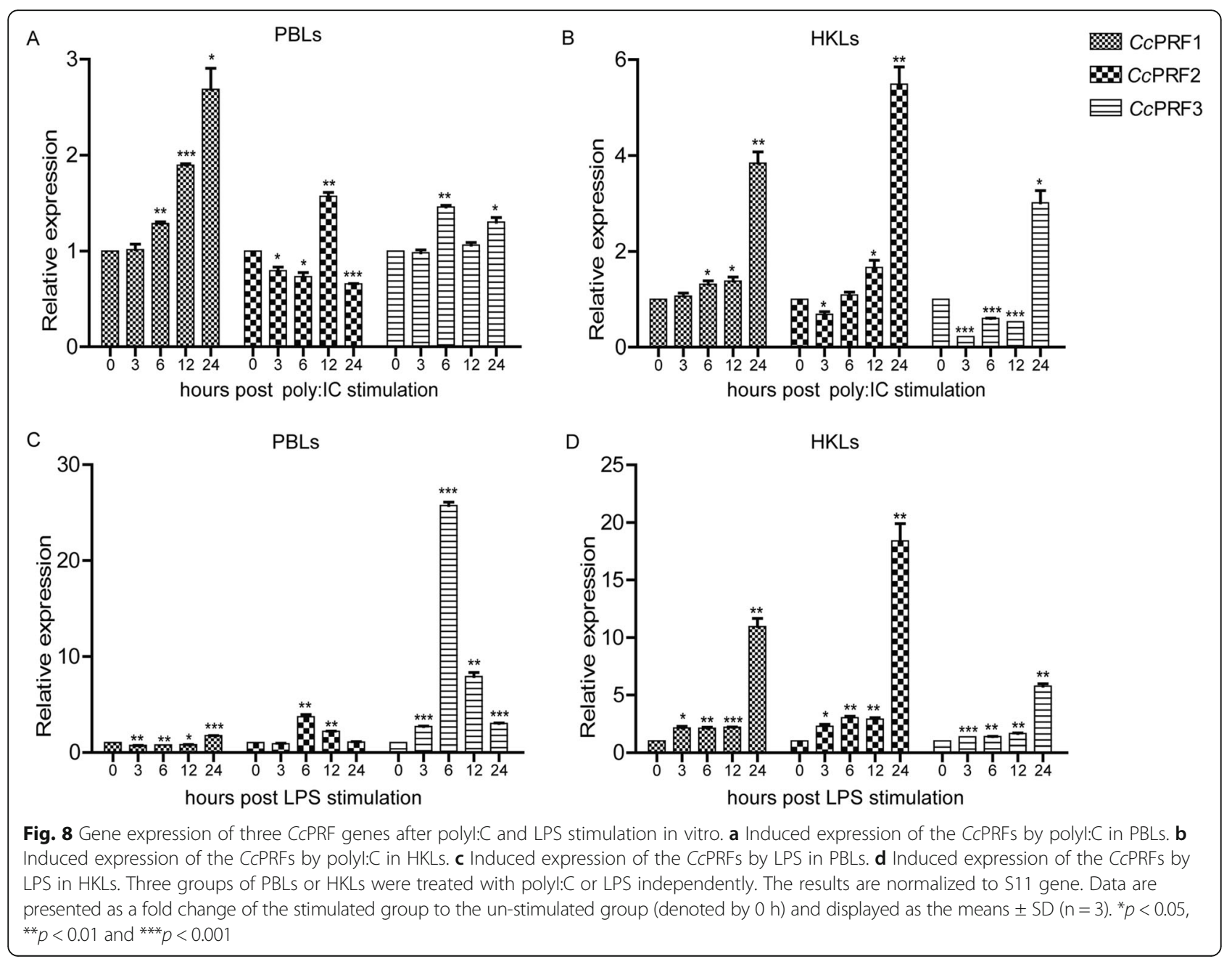



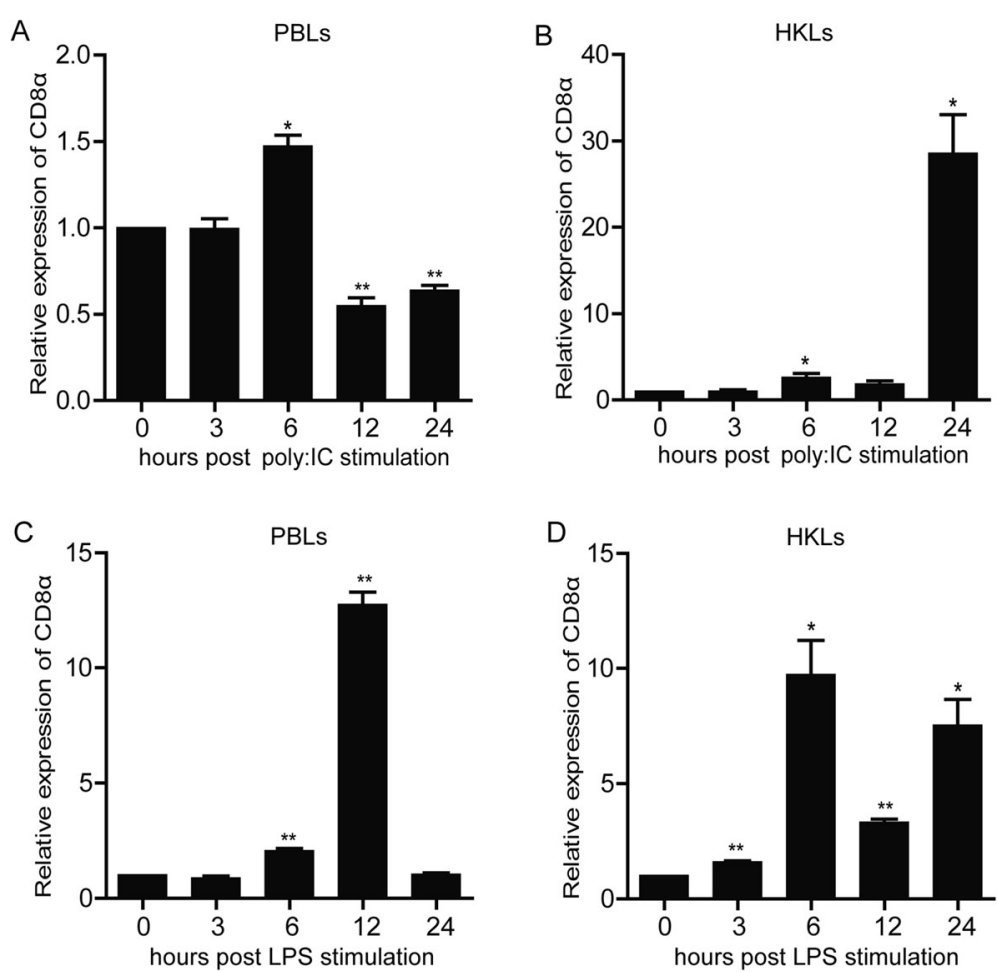

Fig. 9 Gene expression of CD8a after polyl:C and LPS stimulation in vitro. a Induced expression of CD8a by polyl:C in PBLs. $\mathbf{b}$ Induced expression of CD8a by polyl:C in HKLs. $\mathbf{c}$ Induced expression of CD8a by LPS in PBLs. $\mathbf{d}$ Induced expression of CD8a by LPS in HKLs. Three groups of PBLs were treated with polyl:C or LPS independently. The results are normalized to S11 gene. Data are presented as a fold change of the stimulated group to the un-stimulated group (denoted by 0 h) and displayed as the means \pm SD $(n=3) .{ }^{*} p<0.05,{ }^{* *} p<0.01$ and ${ }^{* * *} p<0.001$

common carp larvae, in spite of differential expression patterns for the three $C$ PRRs, they showed a common expression peak at $22 \mathrm{dph}$ (Fig. 5). Moreover, in the larval development of Japanese flounder, perforin gene was significantly expressed during nephron formation [15]. Thus, all the results indicated that together with other immune-related factors, fish perforin may play a crucial role in the larval immune system.

PolyI:C is a mimetic of virus-derived double-stranded RNA, and is usually designed to mimic viral infections $[42,43]$. In mammals, polyI:C or virus was able to induce the expression of perforin in cytotoxic cells. In the mouse hepatic and splenic NK cells [44, 45] and human NK cells isolated from peripheral blood [46], stimulation with polyI:C increased gene expression or protein secretion of the perforin. Using perforin-deficient mice, it was demonstrated that $\mathrm{CD}^{+} \mathrm{T}$ cell-mediated protection against viral infection, such as Ebola virus, West Nile virus and influenza virus, was dependent on perforin [47-49]. In addition, in fish, some studies have reported gene expression of perforin in response to viral stimulation. In the kidney of rock bream injected with rock bream iridovirus (RBIV) or megalocytivirus, significant up-regulation of perforin gene expression was observed at 4 or 8 dpi $[20,21]$. In the rainbow trout RTS11 cell line, infection with viral hemorrhagic septicaemia virus (VHSV) up-regulated perforin gene expression [50]. In the zebrafish kidney, in vivo stimulation with spring viremia of carp virus (SVCV) increased mRNA levels of multiple perforins including PRF1.1, 1.3, 1.5, 1.6 and 1.9 at $6 \mathrm{hpi}$, and polyI:C induced PRF1.6 expression at $3 \mathrm{hpi}$ [22]. Similarly, in common carp, mRNA levels of the three $C c$ PRFs were significantly up-regulated in response to polyl:C in vivo and in vitro (Figs. 6 and 8a, b). However, in contrast to SVCV, polyI:C was not able to increase mRNA levels of zebrafish perforins within $24 \mathrm{hpi}$, with the exception of PRF1.6, in the kidney [22], which was consistent with the in vivo results in common carp. Additionally, rock bream perforin gene was not induced by virus shortly post infection, until a few days later [20, 21]. Moreover, unlike trout RTS11, in the trout HKLs, no significant up-regulation of perforin expression was observed after incubation for $24 \mathrm{~h}$ with VHSV [50]. These data suggested that perforin expression was induced by viral stimulation possibly in a time- and cell population- dependent manner, which may partly explain why in common carp the induction of perforin by polyI:C had the relative tissue-specificity. Nevertheless, in PBLs and HKLs, three CCPRF mRNAs were all up-regulated by polyI:C (Fig. 8a, b). Collectively, all these 
data implied that perforin might play significant roles in the protective host immune response of common carp to virus.

To date only few studies investigated the modulation of perforin gene expression in response to bacterial pathogens, especially the extracellular bacteria. In human NK cells, extracellular mycobacteria induced mRNA and protein production of the perforin, which eliminated the bacteria by damaging cell wall structures [3]. In the fish rohu, stimulation with Gram-negative bacterium A. hydrophila significantly up-regulated expression of perforin gene, particularly in the spleen and gill tissues [51]. Additionally, in the sponge, a cDNA clone resembling human perforin displayed strong antibacterial activaty [52]. Here, in common carp, after stimulation of A. hydrophila, mRNA levels of the three $C c$ PRFs was remarkably enhanced in a variety of immune-related tissues (Fig. 7). Meanwhile, in vitro, stimulation with LPS also increased gene expression of the carp perforins (Fig. 8c, d). Similarly, in the zebrafish adult kidney, significant up-expression of PRF1.1, 1.2, 1.6 and 1.9 was observed over the time course post injection with LPS [22]. LPS is a major component shared in the outer membrane of Gram-negative bacteria, and previous reports showed that LPS was the main virulence factor responsible for the dominant response to Gram-negative bacteria infection [53, 54]. So, based on these data indicating possible relevance of LPS in A. hydrophila-induced up-regulation of $C c$ PRFs. Taken together, all these results suggested potential involvement of perforin in the immune defense of common carp against bacteria.

In mammals, polyI:C or virus was capable of augmenting antigen-specific responses in $\mathrm{CD}^{+} \mathrm{T}$ cells, with inducing perforin expression [55-58]. Moreover, in fish species, a recruitment of $\mathrm{CD} 8 \alpha^{+}$cells was found in the liver of rainbow trout in response to $\mathrm{VHSH}$, meantime with an up-regulation of $\mathrm{CD} 8 \alpha$ and perforin genes observed [59]. Similarly, in rock bream, upon RBIV infection, CD8 $\alpha$ gene expression was increased, accompanied by the induction of perforin at the same time point [21]. As for LPS, via an indirect pathway involving antigen presenting cells (APCs), it is able to promote proliferation and activation of murine $\mathrm{CD}^{+} \mathrm{T}$ cells $[60,61]$. Additionally, in humans, LPS could directly activate naive $\mathrm{CD}^{+} \mathrm{T}$ cells via TLR4 on their cell membranes, and afterwards these activated cells secreted perforin in response to LPS [2]. In line with these findings, in common carp, gene expression of CD8 $\alpha$ (a main marker of teleost CTLs [62]) was increased by polyI:C and LPS in vitro, coincident with the induced expression pattern of perforin. So, based on all these observations, it was inferred that, in common carp, polyI:C and LPS may induce immune activation of $\mathrm{CD}^{+} \mathrm{T}$ cells, after which this type of cells may, at least in part, contribute to the production of perforin in response to immune stimulation.

Besides, it was worth noting that tissue distribution pattern was different for each CcPRF isoform, where CcPRF2 showed broad expression across various tissues, and the other two were more tissue-specific. Additionally, differential expression dynamics were also detected during the larvae ontogeny of common carp (Fig. 5) and in response to immune stimulation (Figs. 6 and 7). As previously reported, the similar phenomenon has been observed in other fish species. In the zebrafish, 6 identified perforin isoforms had diverse constitutive expression patterns in healthy organisms and in larvae ontogeny. And as mentioned above, in the zebrafish kidney, 6 perforins displayed differential response dynamics upon LPS, polyI:C and SVCV [22]. Moreover, in crucian carp CTLs from allo-sensitized fish kidneys, PRF1 mRNA was increased, while PRF2 and PRF3 not changed significantly [19]. These observations raise an interesting question of why fish possess multiple perforin isoforms with different expression dynamics. One explanation is that fish perforins have broader cell distribution and roles or more complex regulatory patterns than in mammals. For instance, perforin is essentially restricted to NK cells and CTLs in mammals, while in fish perforin may be present in more types of immune cells with each isoform being restricted to a particular type. Alternatively, all perforin isoforms may be present in the same cell type, with each responding to distinct signals. Actually, in one previous study, it has been found that multiple isoforms of fish perforins were present at distant loci [63], implying that these perforin genes were likely to be controlled by different regulatory elements. Thus, these facts implied possible different cell locations or functional differences for multiple fish perforin genes, which probably evolved as a strategy to expand immune recognition capabilities in fish and compensate for their limitations of adaptive immunity [64].

\section{Conclusions}

In the present study, three perforin isoform genes, named $C c$ PRF1, $C c$ PRF2 and $C c$ PRF3, were identified and investigated for the first time in common carp. Evolution analysis shows that CcPRF genes have closer evolutionary relationship with other fish perforins than those of mammals, in regard to both amino acid identities and genomic organization. The constitutive expressions of three CcPRFs in early life stages of development imply possible relevance of perforin to the immune system of common carp larvae. Moreover, the significant up-regulation of multiple $C c \mathrm{PRF}$ genes indicate that perforin might play significant roles in the immune defense 
of common carp against viral and bacterial pathogens. Meanwhile, the differential expression dynamics were observed across three $C c$ PRF genes, implying possible different cellular locations or functional differences for various perforin isoforms. These observations could provide some clues for preventing carp infection by pathogenic microorganisms present in the aquatic environment.

\section{Additional files}

\author{
Additional file 1: Table S1. Primers used for CDNA cloning. \\ (DOCX $15 \mathrm{~kb}$ ) \\ Additional file 2: Table S2. Primers used for genomic DNA cloning. \\ (DOCX $14 \mathrm{~kb}$ ) \\ Additional file 3: Table S3. Primers used for Real-time PCR. \\ (DOCX $14 \mathrm{~kb}$ ) \\ Additional file 4: Table S4. GenBank accession numbers for perforin \\ proteins. (DOCX $17 \mathrm{~kb}$ )
}

Additional file 5: Table S5. GenBank accession numbers of Mpeg-1, C6, C7, C8 and C9 proteins. (DOCX $15 \mathrm{~kb}$ )

Additional file 6: Intron and exon sequences of CCPRF1.

(DOCX $13 \mathrm{~kb}$ )

Additional file 7: Intron and exon sequences of CCPRF2.

(DOCX $14 \mathrm{~kb}$ )

Additional file 8: Intron and exon sequences of CCPRF3.

(DOCX $13 \mathrm{~kb}$ )

Additional file 9: Figure S1. Phylogenetic analysis of perforin, Mpeg-1, $\mathrm{C} 6, \mathrm{C} 7, \mathrm{C} 8$ and C9 polypeptides. This tree is generated using the neighborjoining (NJ) method in MEGA 6.0. GenBank accession numbers used are shown in Additional file 4: Tables S4 and Additional file 5: Table S5, and the species abbreviations in Fig. 3. (TIF $29791 \mathrm{~kb}$ )

Additional file 10: ARRIVE (Animal Research: Reporting of in Vivo Experiments) checklist.

\section{Abbreviations \\ A. hydrophila: Aeromonas hydrophila; ANOVA: analysis of variance; APCs: antigen presenting cells; CalB : calcium-binding; CTLs: cytotoxic T lymphocytes; dpf: days post fertilization; dph: days post hatching; EGF: epidermal growth factor; FCS: fetal calf serum; Gzm: granzyme; HKLs: head kidney leukocytes; hpi: hours post injection; JT: Jones-Taylor- Thornton; LPS: lipopolysaccharides; MACPF: membrane-attack-complex/ perforin; Mpeg-1: macrophage-expressed gene 1; NK: natural killer; ORF: open reading frame; PBLs: peripheral blood leukocytes; PBS: phosphate-buffered saline; Polyl:C: polyinosinic-polycytidylic acid; RACE: rapid amplification of the CDNA ends; RBIV: rock bream iridovirus; SMART: simple modular architecture research tool;; SVCV: spring viremia of carp virus; UTR: untranslated region; VHSV: viral hemorrhagic septicaemia virus}

\section{Funding}

This study was supported by National Natural Science Foundation of China (31602186), Shandong Provincial Natural Science Foundation, China (ZR2014CZ004, ZR2014CQ051) and University Independent Innovation Project of Jinan, China (200906020).

\section{Availability of data and materials}

The dataset supporting the conclusions of this article is available in the GenBank and the accession numbers are MH271082, MH271083 and MH271084.

\section{Authors' contributions}

$T L$ and $H L$ participated in the design of the study, performed the experiments, collected data and drafted the manuscript. LW and $\mathrm{YHZ}$ participated in the cloning studies. XYG and XZC helped with the animal experiments. FMZ and GWY performed the statistical analysis. WJW conceived the study and participated in its coordination. All authors read and approved the final manuscript.

\section{Ethics approval and consent to participate}

The protocol was approved by the Animal Experimental Ethics Committee of Shandong Normal University (Permit Number:

AEECSDNU2017005). Additionally, the ARRIVE (Animal Research: Reporting of in Vivo Experiments) checklist has been displayed in Additional file 10.

\section{Consent for publication}

Not applicable.

\section{Competing interests}

The authors declare that they have no competing interests.

\section{Publisher's Note}

Springer Nature remains neutral with regard to jurisdictional claims in published maps and institutional affiliations.

\section{Author details}

'Shandong Provincial Key Laboratory of Animal Resistance Biology, College of Life Sciences, Shandong Normal University, Jinan 250014, China. ${ }^{2}$ Key Laboratory for Sustainable Development of Marine Fisheries, Ministry of Agriculture, Yellow Sea Fisheries Research Institute, Chinese Academy of Fishery Sciences, Qingdao 266071, China. ${ }^{3}$ Laboratory for Marine Fisheries Science and Food Production Processes, Qingdao National Laboratory for Marine Science and Technology, Qingdao 266237, China. ${ }^{4}$ National Life Science and Technology Training Base, Nanjing Agricultural University, Nanjing 210000, China.

Received: 18 May 2018 Accepted: 13 September 2018

Published online: 03 October 2018

\section{References}

1. Kagi D, Ledermann B, Burki K, Seiler P, Odermatt B, Olsen K, Podack ER, Zinkernagel RM, Hengartner H. Cytotoxicity mediated by T cells and natural killer cells is greatly impaired in perforin-deficient mice. Nature. 1994; 369(6475):31-7.

2. Komai-Koma M, Gilchrist DS, Xu D. Direct recognition of LPS by human but not murine CD8+ T cells via TLR4 complex. Eur J Immunol. 2009;39(6):1564-72.

3. Lu CC, Wu TS, Hsu YJ, Chang CJ, Lin CS, Chia JH, Wu TL, Huang TT, Martel J, Ojcius DM, et al. NK cells kill mycobacteria directly by releasing perforin and granulysin. J Leukoc Biol. 2014;96(6):1119-29.

4. Tokmadzic VS, Tomas MI, Sotosek S, Laskarin G, Dominovic M, Tulic V, Dordevic G, Sustic A, Mrakovcic-Sutic I. Different perforin expression in peripheral blood and prostate tissue in patients with benign prostatic hyperplasia and prostate cancer. Scand J Immunol. 2011;74(4):368-76.

5. Alexander AA, Maniar A, Cummings IS, Hebbeler AM, Schulze DH, Gastman BR, Pauza CD, Strome SE, Chapoval Al. Isopentenyl pyrophosphate-activated CD56 + \{gamma\}\{delta\} T lymphocytes display potent antitumor activity toward human squamous cell carcinoma. Clin Cancer Res. 2008;14(13):4232-40.

6. Brown DM, Lee S, Garcia-Hernandez Mde L, Swain SL. Multifunctional CD4 cells expressing gamma interferon and perforin mediate protection against lethal influenza virus infection. J Virol. 2012;86(12):6792-803.

7. Shinkai Y, Takio K, Okumura K. Homology of perforin to the ninth component of complement (C9). Nature. 1988;334(6182):525-7.

8. Lichtenheld MG, Olsen KJ, Lu P, Lowrey DM, Hameed A, Hengartner H, Podack ER. Structure and function of human perforin. Nature. 1988; 335(6189):448-51.

9. Hadders MA, Beringer DX, Gros P. Structure of C8a-MACPF reveals mechanism of membrane attack in complement immune defense. Science. 2007;317(5844):1552

10. Rosado CJ, Buckle AM, Law RHP, Butcher RE, Kan W-T, Bird CH, Ung K, Browne KA, Baran K, Bashtannyk-Puhalovich TA, et al. A common fold mediates vertebrate defense and bacterial attack. Science. 2007;317(5844):1548.

11. Voskoboinik I, Thia MC, Fletcher J, Ciccone A, Browne K, Smyth MJ, Trapani JA. Calcium-dependent plasma membrane binding and cell lysis by perforin are mediated through its $\mathrm{C} 2$ domain: a critical role for aspartate residues 429, 435, 483, and 485 but not 491. J Biol Chem. 2005;280(9):8426-34.

12. Liu CC, Young LH, Young JD. Lymphocyte-mediated cytolysis and disease. N Engl J Med. 1996;335(22):1651-9.

13. Gordy C, He YW. Endocytosis by target cells: an essential means for perforin- and granzyme-mediated killing. Cell Mol Immunol. 2012;9(1):5-6. 
14. Podack ER, Young JD, Cohn ZA. Isolation and biochemical and functional characterization of perforin 1 from cytolytic T-cell granules. Proc Natl Acad Sci U S A. 1985;82(24):8629-33.

15. Yang H, Lee YM, Lee JH, Noh JK, Kim HC, Park CJ, Park JW, Hwang IJ, Kim SY. Expression of perforin gene for early development of nephrons in olive flounder (Paralichthys olivaceus). Dev Reprod. 2013;17(4):321-7.

16. Hwang JY, Ohira T, Hirono I, Aoki T. A pore-forming protein, perforin, from a non-mammalian organism, Japanese flounder, Paralichthys olivaceus. Immunogenetics. 2004;56(5):360-7.

17. Taylor EB, Moulana M, Stuge TB, Quiniou SMA, Bengten E, Wilson M. A Leukocyte Immune-Type Receptor Subset Is a Marker of Antiviral Cytotoxic Cells in Channel Catfish, Ictalurus punctatus. J Immunol. 2016;196(6):2677.

18. Athanasopoulou S, Marioli D, Mikrou A, Papanastasiou AD, Zarkadis IK. Cloning and characterization of the trout perforin. Fish Shellfish Immunol. 2009:26(6):908-12.

19. Toda H, Araki K, Moritomo T, Nakanishi T. Perforin-dependent cytotoxic mechanism in killing by CD8 positive T cells in ginbuna crucian carp, Carassius auratus langsdorfii. Dev Comp Immunol. 2011;35(1):88-93.

20. Jung MH, Nikapitiya C, Song JY, Lee JH, Lee J, Oh MJ, Jung SJ. Gene expression of pro- and anti-apoptotic proteins in rock bream (Oplegnathus fasciatus) infected with megalocytivirus (family Iridoviridae). Fish Shellfish Immunol. 2014;37(1):122-30.

21. Jung MH, Jung SJ. CpG ODN 1668 induce innate and adaptive immune responses in rock bream (Oplegnathus fasciatus) against rock bream iridovirus (RBIV) infection. Fish Shellfish Immunol. 2017;69:247-57.

22. Varela M, Forn-Cuní G, Dios S, Figueras A, Novoa B. Proinflammatory caspase a activation and an antiviral state are induced by a zebrafish perforin after possible cellular and functional diversification from a myeloid ancestor. J Innate Immun. 2016;8(1):43-56.

23. Companjen A, Heinhuis B, Aspers K, Rombout J. In vivo evoked specific cell mediated cytotoxicity in carp (Cyprinus carpio L.) uses mainly a perforin/ granzyme-like pathway. Fish Shellfish Immunol. 2006;20(1):113-7.

24. Li H, Li T, Guo Y, Li Y, Zhang Y, Teng N, Zhang F, Yang G. Molecular characterization and expression patterns of a non-mammalian toll-like receptor gene (TLR21) in larvae ontogeny of common carp (Cyprinus carpio L.) and upon immune stimulation. BMC Vet Res. 2018;14(1):153.

25. Shan SJ, Liu DZ, Wang L, Zhu YY, Zhang FM, Li T, An LG, Yang GW. Identification and expression analysis of irak1 gene in common carp Cyprinus carpio L.: indications for a role of antibacterial and antiviral immunity. J Fish Biol. 2015;87(2):241-55.

26. Li H, Yang G, Ma F, Li T, Yang H, Rombout JHWM, An L. Molecular characterization of a fish-specific toll-like receptor 22 (TLR22) gene from common carp (Cyprinus carpio L.): Evolutionary relationship and induced expression upon immune stimulants. Fish Shellfish Immunol. 2017;63:74-86.

27. Shan S, Liu R, Jiang L, Zhu Y, Li H, Xing W, Yang G. Carp toll-like receptor 8 (TIr8): an intracellular TIr that recruits TIRAP as adaptor and activates AP-1 pathway in immune response. Fish Shellfish Immunol. 2018;82:41-9.

28. Zhu YY, Xing WX, Shan SJ, Zhang SQ, Li YQ, Li T, An L, Yang GW. Characterization and immune response expression of the rig-l-like receptor mda5 in common carp Cyprinus carpio. J Fish Biol. 2016;88(6):2188-202.

29. Shan S, Liu D, Liu R, Zhu Y, Li T, Zhang F, An L, Yang G, Li H. Nonmammalian toll-like receptor 18 (Tlr18) recognizes bacterial pathogens in common carp (Cyprinus carpio L.): indications for a role of participation in the NF-kappaB signaling pathway. Fish Shellfish Immunol. 2018;72:187-98.

30. Li H, Zhang F, Guo H, Zhu Y, Yuan J, Yang G, An L. Molecular characterization of hepcidin gene in common carp (Cyprinus carpio L.) and its expression pattern responding to bacterial challenge. Fish Shellfish Immunol. 2013;35(3):1030-8.

31. Shan S, Qi C, Zhu Y, Li H, An L, Yang G. Expression profile of carp IFN correlate with the up-regulation of interferon regulatory factor-1 (IRF-1) in vivo and in vitro: the pivotal molecules in antiviral defense. Fish Shellfish Immunol. 2016;52:94-102.

32. Li T, Li H, Peng S, Zhang F, An L, Yang G. Molecular characterization and expression pattern of X box-binding protein-1 (XBP1) in common carp (Cyprinus carpio L.): indications for a role of XBP1 in antibacterial and antiviral immunity. Fish Shellfish Immunol. 2017;67:667-74.

33. Livak KJ, Schmittgen TD. Analysis of relative gene expression data using realtime quantitative $P C R$ and the $2-\Delta \Delta C T$ method. Methods. 2001;25(4):402-8.

34. Shinkai Y, Yoshida MC, Maeda K, Kobata T, Maruyama K, Yodoi J, Yagita H, Okumura K. Molecular cloning and chromosomal assignment of a human perforin (PFP) gene. Immunogenetics. 1989;30(6):452-7.
35. Kwon BS, Wakulchik M, Liu CC, Persechini PM, Trapani JA, Haq AK, Kim Y, Young JD. The structure of the mouse lymphocyte pore-forming protein perforin. Biochem Biophys Res Commun. 1989;158(1):1-10.

36. Law RHP, Lukoyanova N, Voskoboinik I, Caradoc-Davies TT, Baran K Dunstone MA, ME D'A, Orlova EV, Coulibaly F, Verschoor S, et al. The structural basis for membrane binding and pore formation by lymphocyte perforin. Nature. 2010;468(7322):447-51.

37. Cecchini S, Paciolla M, Biffali E, Borra M, Ursini MV, Lioi MB. Ontogenetic profile of innate immune related genes and their tissue-specific expression in brown trout, Salmo trutta (Linnaeus, 1758). Fish Shellfish Immunol. 2013; 35(3):988-92.

38. Huttenhuis HB, Grou CP, Taverne-Thiele AJ, Taverne N, Rombout JH. Carp (Cyprinus carpio L.) innate immune factors are present before hatching. Fish Shellfish Immunol. 2006;20(4):586-96.

39. Nayak SP, Mohanty BR, Mishra J, Rauta PR, Das A, Eknath AE, Sahoo PK Ontogeny and tissue-specific expression of innate immune related genes in rohu, Labeo rohita (Hamilton). Fish Shellfish Immunol. 2011;30(4-5):1197-201.

40. Huttenhuis HB, Taverne-Thiele AJ, Grou CP, Bergsma J, Saeij JP, Nakayasu C, Rombout JH. Ontogeny of the common carp (Cyprinus carpio L.) innate immune system. Dev Comp Immunol. 2006;30(6):557-74.

41. Lam SH, Chua HL, Gong Z, Lam TJ, Sin YM. Development and maturation of the immune system in zebrafish, Danio rerio: a gene expression profiling, in situ hybridization and immunological study. Dev Comp Immunol. 2004; 28(1):9-28.

42. Matsumoto M, Seya T. TLR3: interferon induction by double-stranded RNA including poly(l:C). Adv Drug Deliv Rev. 2008;60(7):805-12.

43. Zhu Y, Qi C, Shan S, Zhang F, Li H, An L, Yang G. Characterization of common carp (Cyprinus carpio L.) interferon regulatory factor 5 (IRF5) and its expression in response to viral and bacterial challenges. BMC Vet Res. 2016; 12(1):127.

44. Bao Y, Zheng J, Han C, Jin J, Han H, Liu Y, Lau YL, Tu W, Cao X. Tyrosine kinase Btk is required for NK cell activation. J Biol Chem. 2012;287(28): 23769-78.

45. Pan HN, Sun R, Jaruga B, Hong F, Kim WH, Gao B. Chronic ethanol consumption inhibits hepatic natural killer cell activity and accelerates murine cytomegalovirus-induced hepatitis. Alcohol Clin Exp Res. 2006;30(9): 1615-23.

46. Muller L, Chehrazi CV, Henderson MW, Noah TL, Jaspers I. Diesel exhaust particles modify natural killer cell function and cytokine release. Part Fibre Toxicol. 2013;10:16.

47. Gupta M, Greer P, Mahanty S, Shieh WJ, Zaki SR, Ahmed R, Rollin PE. CD8mediated protection against Ebola virus infection is perforin dependent. J Immunol (Baltimore, Md : 1950). 2005;174(7):4198-202.

48. Topham DJ, Tripp RA, Doherty PC. CD8+ T cells clear influenza virus by perforin or Fas-dependent processes. J Immunol (Baltimore, Md : 1950). 1997;159(11):5197-200

49. Shrestha B, Samuel MA, Diamond MS. CD8+ T cells require perforin to clear West Nile virus from infected neurons. J Virol. 2006;80(1):119-29.

50. Ordas MC, Cuesta A, Mercado L, Bols NC, Tafalla C. Viral hemorrhagic septicaemia virus (VHSV) up-regulates the cytotoxic activity and the perforin/granzyme pathway in the rainbow trout RTS11 cell line. Fish Shellfish Immunol. 2011;31(2):252-9.

51. Robinson N, Baranski M, Mahapatra KD, Saha JN, Das S, Mishra J, Das P, Kent M, Arnyasi M, Sahoo PK. A linkage map of transcribed single nucleotide polymorphisms in rohu (Labeo rohita) and QTL associated with resistance to Aeromonas hydrophila. BMC Genomics. 2014;15:541.

52. Thakur N, Hentschel U, Krasko A, Pabel CT, Anil A, Mueller WEG Antibacterial activity of the sponge Suberites domuncula and its primmorphs: Potential basis for epibacterial chemical defense. vol. 31; 2003.

53. Nau GJ, Schlesinger A, Richmond JF, Young RA. Cumulative Toll-like receptor activation in human macrophages treated with whole bacteria. Immunol (Baltimore, Md : 1950). 2003;170(10):5203-9.

54. Nau GJ, Richmond JF, Schlesinger A, Jennings EG, Lander ES, Young RA. Human macrophage activation programs induced by bacterial pathogens. Proc Natl Acad Sci U S A. 2002;99(3):1503-8

55. Salem ML, Diaz-Montero CM, El-Naggar SA, Chen Y, Moussa O, Cole DJ. The TLR3 agonist poly $(\mathrm{l}: \mathrm{C})$ targets CD8+ T cells and augments their antigenspecific responses upon their adoptive transfer into naive recipient mice. Vaccine. 2009;27(4):549-57

56. Jenkins MR, Mintern J, La Gruta NL, Kedzierska K, Doherty PC, Turner SJ. Cell cycle-related acquisition of cytotoxic mediators defines the progressive 
differentiation to effector status for virus-specific CD8+ T cells. J Immunol (Baltimore, Md : 1950). 2008;181(6):3818-22.

57. Caetano J, Martinho A, Paiva A, Pais B, Valente C, Luxo C. Differences in hepatitis $C$ virus (HCV)-specific CD8 T-cell phenotype during pegylated alpha interferon and ribavirin treatment are related to response to antiviral therapy in patients chronically infected with HCV. J Virol. 2008;82(15):7567-77.

58. Hersperger AR, Makedonas G, Betts MR. Flow cytometric detection of perforin upregulation in human CD8 T cells. Cytometry A. 2008;73(11):1050-7.

59. Castro R, Abos B, Pignatelli J, von Gersdorff JL, Gonzalez Granja A, Buchmann K, Tafalla C. Early immune responses in rainbow trout liver upon viral hemorrhagic septicemia virus (VHSV) infection. PLoS One. 2014;9(10):e111084.

60. Castro A, Bemer V, Nobrega A, Coutinho A, Truffa-Bachi P. Administration to mouse of endotoxin from gram-negative bacteria leads to activation and apoptosis of T lymphocytes. Eur J Immunol. 1998;28(2):488-95.

61. Tough DF, Sun S, Sprent J. T cell stimulation in vivo by lipopolysaccharide (LPS). J Exp Med. 1997;185(12):2089-94.

62. Nakanishi T, Toda H, Shibasaki Y, Somamoto T. Cytotoxic T cells in teleost fish. Dev Comp Immunol. 2011;35(12):1317-23.

63. D'Angelo ME, Dunstone MA, Whisstock JC, Trapani JA, Bird PI. Perforin evolved from a gene duplication of MPEG1, followed by a complex pattern of gene gain and loss within Euteleostomi. BMC Evol Biol. 2012;12:59.

64. Sunyer JO, Zarkadis IK, Lambris JD. Complement diversity: a mechanism for generating immune diversity? Immunol Today. 1998;19(11):519-23.

Ready to submit your research? Choose BMC and benefit from:

- fast, convenient online submission

- thorough peer review by experienced researchers in your field

- rapid publication on acceptance

- support for research data, including large and complex data types

- gold Open Access which fosters wider collaboration and increased citations

- maximum visibility for your research: over $100 \mathrm{M}$ website views per year

At $\mathrm{BMC}$, research is always in progress.

Learn more biomedcentral.com/submissions 